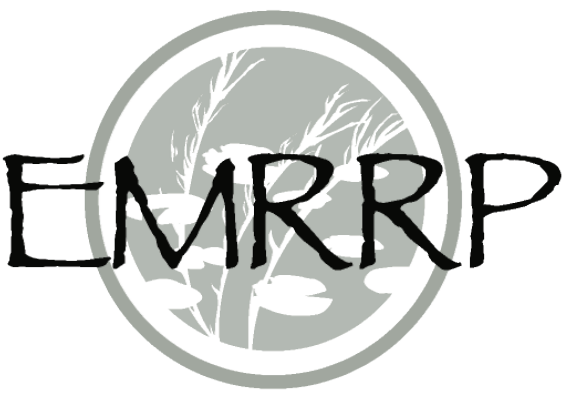

\title{
Approaches to Identify and Monitor for Potential Acid Sulfate Soils in an Ecological Restoration Context
}

\author{
by Jacob F. Berkowitz and Christine M. VanZomeren
}

PURPOSE: Potential acid sulfate soils include materials with the capacity to generate acidity under certain environmental conditions. As such, these soils can pose challenges to ecological restoration projects occurring in wetlands and nearshore environments. To provide guidance for ecosystem restoration practitioners, the following technical note describes acid sulfate soil formation and distribution and then describes techniques for identifying and monitoring acid sulfate soil conditions prior to and following implementation of restoration activities. Finally, this technical note outlines a number of tools and recently published resources to help avoid unintended consequences of acid sulfate soil disturbance and achieve ecological restoration objectives.

BACKGROUND: Ecological restoration projects occur in a variety of wetland and aquatic environments, including marshes, floodplains, estuaries, and depressional landscape features (Zedler 2000). Historic landscape alterations have disproportionately affected wetlands, resulting in a $>50 \%$ decline in wetland extent within the conterminous United States (Dahl 2011) and therefore numerous restoration activities in and around these ecosystems. Increasingly, government agencies, the private sector, and the general public have recognized the ecological functions provided by wetlands - and the need to restore those lost functions. For example, wetlands provide critical habitat for nearly half of all threatened and endangered species despite occupying only $\sim 5.5 \%$ of the landscape (Flynn 1995). Further, wetlands also provide services and values that benefit society, such as reductions in storm surge and flood risk, improvements to water quality, and opportunities for recreation (Novitski, Smith, and Fretwell 1996). The abundance of opportunities to conduct ecological restoration, the outsized role of habitat and ecological functions associated with wetlands, and the capacity to use natural processes to protect human infrastructure and populations work in concert to promote restoration and enhancement of wetlands ecosystems (Kurth et al. 2020).

Conducting restoration activities in wetlands poses distinct challenges related to physical, biological, and chemical factors that must be considered during restoration design, implementation, and monitoring. The following addresses two of the challenges that can hinder wetland restoration: the occurrence of potential acid sulfate soils within a restoration project area and the formation of acid-bearing materials in response to restorative actions.

ACID SULFATE SOILS: Soils provide the physical substrate upon which wetlands develop, and on which restoration projects occur. Soil characteristics reflect complex and dynamic equilibria with respect to the underlying geology on which a soil forms; the flora and fauna living on (and inside of) the soil; the location of the soil within the surrounding landscape; temporal effects of disturbance, deposition, and erosion; and the multidirectional movement of water, nutrients, and other materials within the soil system (Jenny 2012). As a result, wetland soils develop unique 
morphological, physical, and biological traits that occur in areas subject to prolonged periods of inundation or saturation (Vepraskas and Craft 2016).

Wetlands are characterized by the presence of hydrology, hydrophytic vegetation, and hydric soils (NRC 1995); and hydric soils are defined as those soils that experience inundation or saturation sufficient to develop anaerobic conditions in the upper portion of the soil profile (NTCHS 2015). Anaerobic conditions are induced when organic matter is decomposed during microbial respiration, a process that consumes oxygen. Once the available oxygen concentration in soil pore water is depleted, microbial respiration continues through the use of alternative electron acceptors (AEAs), resulting in the reduction of their oxidation state (that is, chemical reduction). For example, soluble nitrogen oxides $\left(\mathrm{NO}_{\mathrm{x}}\right)$ are reduced to nitrogen gas, ${ }^{1}$ a variety of iron oxide and oxyhydroxide solids (for example, $\mathrm{Fe}_{2} \mathrm{O}_{3}, \mathrm{FeOOH}$ ) are reduced to soluble ferrous $\left(\mathrm{Fe}^{2+}\right)$ iron, and sulfate compounds $\left(\mathrm{SO}_{4}{ }^{2-}\right)$ are reduced to dissolved sulfides $\left(\mathrm{S}^{2-}\right)$.

These changes in pore-water chemistry have important implications for wetland ecosystems, including the productivity of plants, soil morphology, and soil chemistry. For example, the conversion of nitrates to nitrogen gas (that is, denitrification) has been recognized as an important mechanism to reduce nutrient loading and improve regional water quality (Mitsch et al. 2001). Conversely, the presence of sulfide, a phytotoxin, in soil pore water has been linked with decreased plant productivity, germination, and increased mortality (Koch et al. 1990).

Sulfides react rapidly to form hydrogen sulfide $\left(\mathrm{H}_{2} \mathrm{~S}\right)$ gas, which many practitioners have experienced walking through coastal marshes or other wetlands as a strong rotten egg odor. In the presence of ferrous iron, sulfides rapidly form insoluble iron sulfide (FeS) complexes that precipitate as distinct dark grey or black coatings on soil particles (figure 1; Rabenhorst, Burch, and Fanning 2002). Formation of the iron sulfide precipitates decreases the potential toxic effects to plants associated with free sulfides while providing a morphologic feature that is readily observable on the soil surface or with excavation of the surface soil layers (VanZomeren et al. 2020).

Once established, the iron sulfide precipitates remain stable under scenarios where anaerobic conditions persist (that is, prolonged periods of soil inundation or saturation during which oxidation does not occur). However, if oxygen becomes available and oxidation of the iron sulfide compounds occur, these materials have the potential to generate acidity (Rabenhorst and Fanning 2002). The oxidation of FeS materials generates sulfuric acid, a strong acid (equation 1). Additional acidity may also be produced during the hydration of iron oxides. Previous studies have reported potential shifts in soil $\mathrm{pH}$ during FeS oxidation from circumneutral values to commonly below 4.0, and in some cases below 2.0 (Berkowitz et al. 2020). These low pH conditions can damage plant materials, resulting in decreased growth rates or inducing mortality (Berkowitz and VanZomeren 2020). The low $\mathrm{pH}$ values can also negatively affect water quality and faunal populations within a project location as well as in the surrounding area (Melville and White 2002). As a result of their potential to generate acidity, soils containing oxidizable sulfide such as FeS are known as potential acid sulfate soils.

1. For a full list of the spelled-out forms of the chemical elements used in this document, please refer to US Government Publishing Office Style Manual, 31 sted. (Washington, DC: US Government Publishing Office, 2016), 265, https://www.govinfo.gov/content/pkg/GPO-STYLEMANUAL-2016/pdf/GPO-STYLEMANUAL-2016.pdf. 
$\mathrm{FeS}_{2}(\mathrm{~s})+3.75 \mathrm{O}_{2}+3.5 \mathrm{H}_{2} \mathrm{O} \rightarrow$ oxidizing conditions $\rightarrow 2 \mathrm{H}_{2} \mathrm{SO}_{4}(\mathrm{aq})+\mathrm{Fe}(\mathrm{OH})_{3}(\mathrm{~s})(1)$

The oxidation of these soils (and subsequent generation of acidity) can occur naturally following droughts, when water tables decrease, and oxygen is introduced to soils and sediments that would otherwise remain inundated during periods of normal hydrology. Alternatively, oxidation can also occur following a disturbance that alters the environmental conditions of the soil material, including activities that may occur during ecological restoration efforts, such as the dredging of anaerobic sediments containing acid sulfate materials with subsequent oxidation following exposure to the atmosphere. The excavation of materials can also induce acidification if the newly exposed surfaces come into contact with the atmosphere and oxidation occurs. Additionally, activities that alter the hydrology of an area through drainage or diking can alter the oxidation status of potential acid sulfate soils.

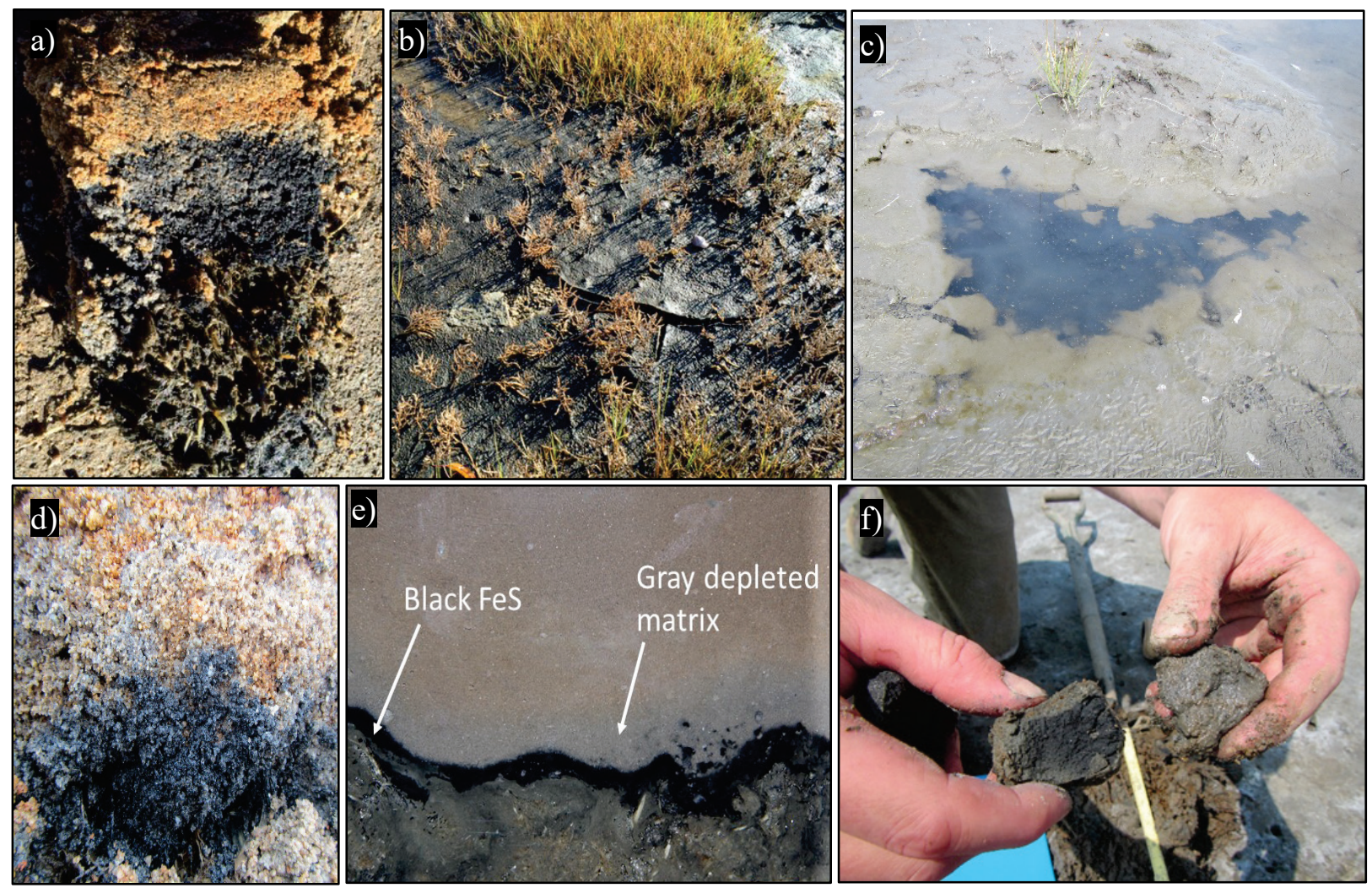

Figure 1. Examples of iron sulfide (FeS) soil morphology, in which the dark-colored materials occur (a) across multiple soil horizons in the soil profile, $(b)$ at the soil surface, $(c)$ as black ooze, $(d)$ as concentrations of dark materials distributed within the soil profile, or $(e)$ as a thin layers within the soil profile; $(f)$ these dark features will degrade rapidly upon exposure to air or chemical oxidants, as seen in the paired unoxidized (black) and oxidized (grey) soil aggregates.

Acid sulfate conditions are also associated with current and historic mining operations, which results in acid-mine drainage. However, this technical note does not address issues related to manipulation of materials far below the surface (for example, hardrock mining operations), and instead focuses on activities occurring in soils and sediments as part of natural resource restoration activities. 
Restoration projects often alter the landscape to achieve project objectives, including the grading of landscapes to mimic natural landforms, the use of dredged sediment to create habitat on islands and in nearshore environments, the excavation and removal of materials to restore historic inundation patterns, and the manipulation of hydrology to recreate natural connections to water bodies. These activities have the potential to expose acid sulfate soils to oxidizing conditions, which can have significant implications for restoration project success. Fortunately, techniques, tools, and strategies exist to address the challenges associated with acid sulfate soils.

Additionally, recent research has documented the development of potential acid sulfate soils following restoration activities (Berkowitz and VanZomeren 2020), including several projects located in New England, in mid-Atlantic states, and in California. Under simulated laboratory conditions, the placement of dredged sediments onto marsh soils resulted in the formation of iron sulfide soil materials within 16 days. Subsequent oxidation of those materials following the removal of inundation decreased the soil $\mathrm{pH}$ from 7.0 to 4.5 over the period of several weeks (Berkowitz et al. 2019). Interestingly, neither the dredged materials nor the marsh soils contained iron sulfides prior to the experiment, suggesting that restoration activities can result in the formation of potential acid sulfate soils under some scenarios. As more restoration projects seek to supplement the elevation of marshes and other landscape features in response to subsidence, relative sea level rise, or other concerns, practitioners need to remain cognizant of implications related to potential acid sulfate soil development.

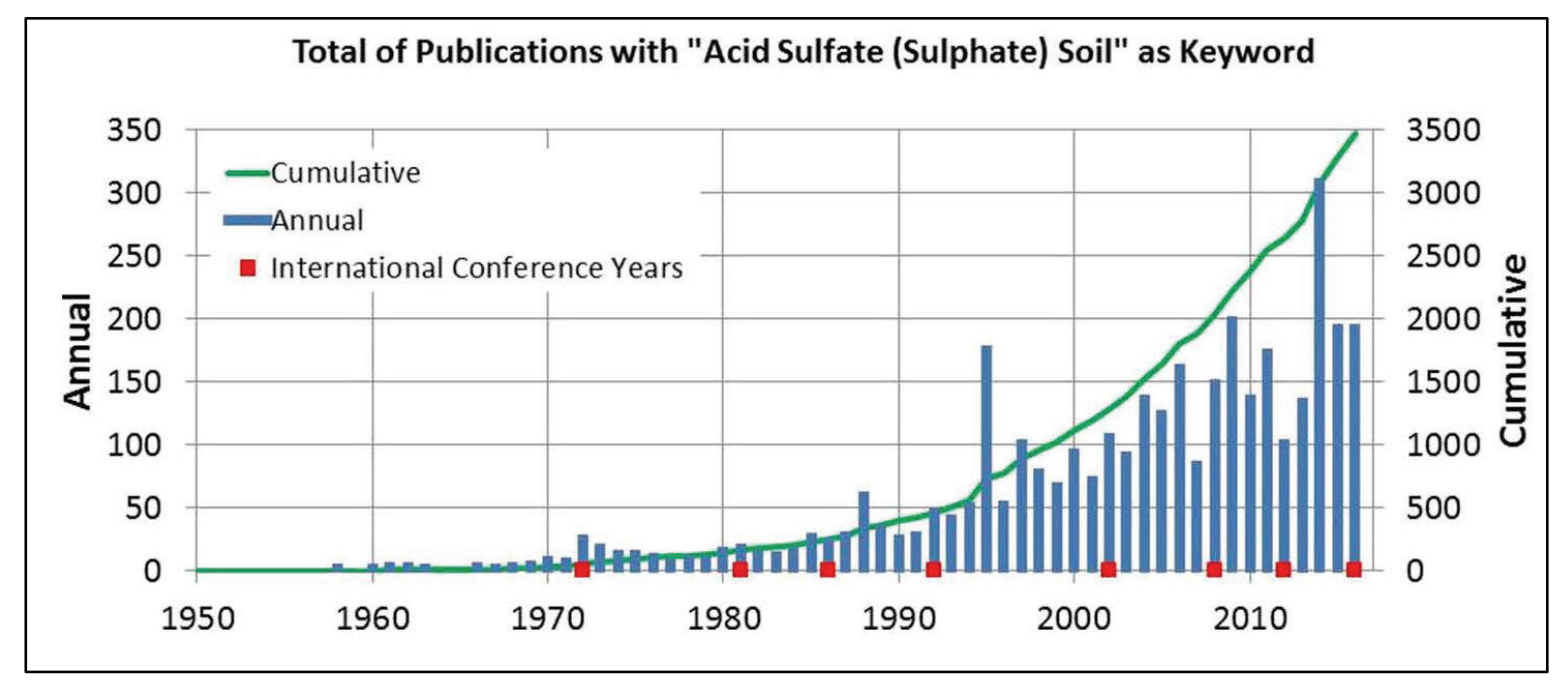

Figure 2. Increase in journal publications related to acid sulfate soils, highlighting the growing need for additional research and guidance for managing these soil materials (from Fanning, Rabenhorst, and Fitzpatrick 2017, 192).

Research into the formation, oxidation, and management of acid sulfate soils has increased dramatically in recent years, as seen in the rise in publications on this topic (figure 2). These studies have improved our awareness of acid sulfide soils and yield valuable resources to help (1) prevent soil acidification through the proper identification and management of these materials and (2) remediate areas where soil acidification has occurred. However, communicating these challenges to practitioners still requires significant additional outreach, especially within an ecological restoration context. 
DISTRIBUTION OF ACID SULFATE SOILS: Acid sulfate soils occupy an estimated 12-15 million hectares of land area across the globe (Fanning 2002; Andriesse2001). These soil materials occur in many regions of the United States, including across several mid-Atlantic, New England, Southeastern, and Gulf Coast states. These materials have also been documented in the Caribbean Islands and Puerto Rico, California, Alaska, Nebraska, Colorado, New Mexico, Wyoming, and other areas. Figure 3 provides regional maps from select areas of the estimated spatial extent of acid sulfate soils and the geologic formations that may contain these materials. However, no comprehensive map or other resource currently exists depicting the occurrence of these materials across the United States, and very few of the available maps offer the detail required to discern conditions at restoration-project scales.

While the full extent of acid sulfate remains unknown, tools do exist to identify potential acidbearing materials on the landscape. Soil survey data contain taxonomic designations that suggest the potential for acid sulfate occurrence, including references to sulfidic material, sulfuric horizon, or the following modifiers: sulfaquents, sulfaquepts, sulfaquerts, sulfidic materials, sulfihemists, sulfisaprists, sulfohemists, sulfosaprists, sulfudepts, or sulfuric horizon (USDA-NRCS 2010). If these soil designations occur within a restoration project area, further analysis is recommended. Note that the utility of soil survey data for identifying potential acid sulfate soils is limited in many coastal and nearshore zones, because comprehensive soil mapping has not been conducted in some areas and efforts to map subaqueous soils have only recently begun. The lack of comprehensive maps results in a paucity of data related to the extent of these soil materials. However, the benefits of mapping subaqueous and nearshore soil environments have been recognized, and more information about the distribution of acid sulfate soils is anticipated in the future (Wessel et al. 2018).
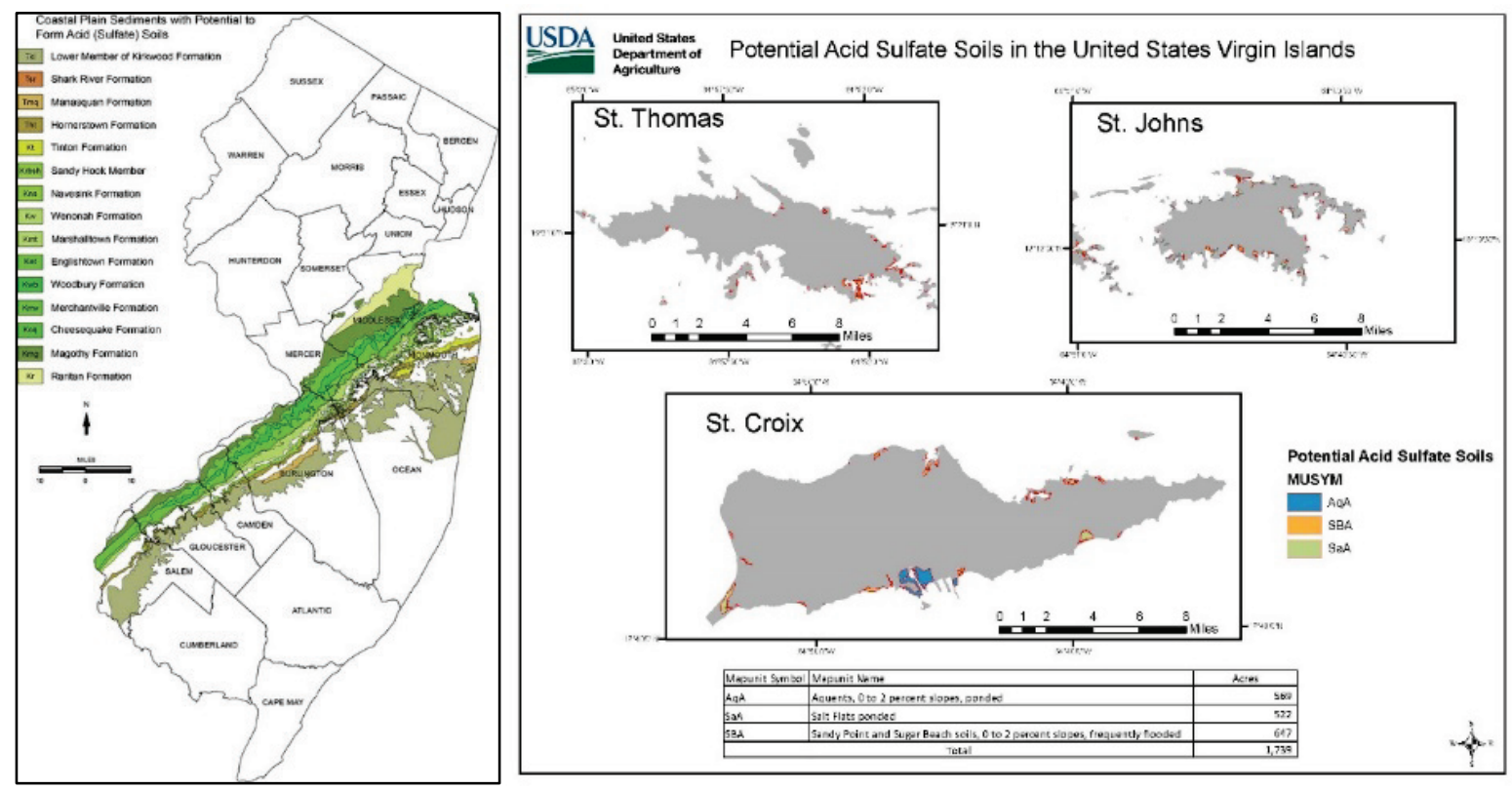

Figure 3. Examples of maps indicating the estimated distribution of potential acid sulfate soils, or geologies associated with acid sulfate conditions in New Jersey (left, from NJDEP 2015) and the US Virgin Islands (right, from USDA-NRCS 2019). 
IDENTIFICATION OF ACID SULFATE SOILS: There are several techniques for identifying acid sulfate soils under both field and laboratory conditions. Below, we summarize common techniques for identifying acid sulfate soils in the field first, then we discuss options for laboratory approaches. Subsequent sections provide guidance for applying these techniques to effectively manage these soil materials in a restoration context.

Field identification techniques. A recent publication by Duball et al. (2020) provides the most up-to-date guidance for identifying acid sulfate soils using rapid and reliable field procedures. These approaches are summarized in figure 4 . The field procedures include (1) evaluating soil morphology to confirm the presence of dark grey to black soil materials indicative of iron sulfide precipitates; (2) application of dilute hydrogen peroxide $\left(\mathrm{H}_{2} \mathrm{O}_{2}\right)$ or prolonged exposure to air to initiate oxidation of the iron sulfides, which induces color change; and (3) application of hydrochloric acid $(\mathrm{HCl})$, which generates the distinct rotten-egg odor in the presence of iron sulfide compounds. Each of these techniques is rapid, inexpensive, and can be applied in combination to document the presence of potential acid sulfate soils. This instructional two-minute video demonstrates for field practitioners how to apply these three techniques: https://www.youtube.com/watch?v=D6ZUvTNUre0.

Technique 1: Evaluating soil morphology. A simple evaluation using a Munsell color chart should be conducted to evaluate any dark soil materials within a restoration project location. The evaluation can also be conducted on any soil or sediment materials derived from off-site sources that will be used during the restoration project (for example, dredged materials, soil transported from another location). Potential acid sulfate soils are characterized by their distinct dark grey to black colors. These soil materials typically have Munsell values $\leq 4.0$ and a Munsell chroma $\leq 1.0$. The Munsell hue varies, but neutral hues are commonly encountered. Note that the presence of iron sulfides occurs in a variety of morphologic patterns. In some cases, the dark iron sulfide coatings cover large portions of the soil profile (figure 1). Alternatively, the dark grey to black material may be observed at the soil surface or just below the soil surface, in a single layer within the soil profile, or as inclusion of dark materials scatter within the soil matrix. The dark-colored features may also occur along root channels and soil cracks or in areas where organic matter has been deposited (or buried). The dark materials may also be observed as black ooze or in the footprints of practitioners traversing a marsh or other area. In the field it is important to document the soil color as quickly as possible after excavation because soil can change color quickly once it is exposed to the atmosphere and oxidation is initiated.

Technique 2: Application of hydrogen peroxide or prolonged exposure to the atmosphere. When potential acid sulfate soils are exposed to oxidizing agents, the dark-colored iron sulfide precipitates rapidly deteriorate, exposing the underlying soil surface. This oxidation process can be induced through the application of dilute (typically 3\%) hydrogen peroxide (available at drug stores and other retail outlets). In the field, users should excavate the soil and record the soil colors as described above. Then, using a spray bottle or dropper, apply hydrogen peroxide to the dark portions of the soil profile. If iron sulfides are present, an instantaneous color change will occur, and the soil will shift to a higher Munsell value and (often) a higher Munsell chroma. The new soil color should be recorded for documentation purposes to indicate whether a color shift was observed. While the application of hydrogen peroxide is preferred, the presence of iron sulfides can also be documented by simply exposing the soil to the atmosphere for a period of $0.5-1.0 \mathrm{~h}$. As above, make sure to record the soil colors immediately after excavation and again 
after any color shifts have occurred following atmospheric exposure. Dilute hydrogen peroxide poses minimal safety risks to practitioners but should be maintained in a clearly labeled container, and care should be taken to avoid ingestion or eye contact and to limit exposure to skin and clothing.

Technique 3: Application of hydrochloric acid. The application of $1 \mathrm{M}$ hydrochloric acid results in the rapid evolution of hydrogen sulfide gas, which is easily identified by its distinct rotten-egg odor. To conduct this method in the field, excavate and record the soil color as above. Then carefully place several drops of the acid onto the dark soil materials and waft the air above the soil towards your nose. The reaction is very rapid (nearly instantaneous), so make sure that you are ready to smell immediately following acid application. The human nose has a very low detection limit for hydrogen sulfide gas, so the presence of the gas is generally immediately apparent. Alternatively, if the presence of high winds prevents you from smelling the rotten-egg odor, place the soil into a sealable plastic bag, or test tube, place a few drops of acid into the vessel and seal the bag or tube for a short period $(\sim 1 \mathrm{~min})$. Then open the vessel and waft the fumes towards your nose. Take care to properly dispose of the vessel, as it will impart the rotten-egg odor to vehicles, backpacks, coat pockets, or other items if left unattended. Hydrochloric acid is available through a variety of laboratory supply stores. Note that while $1 \mathrm{M}$ hydrochloric acid is not considered a concentrated acid, caution should be used when handling. It can irritate skin upon exposure and can damage clothing and other materials. It also poses a health risk if ingested or if it comes into contact with the eyes. The acid should be stored and transported in a sturdy glass container with a tight-fitting lid and should be properly labeled. 
FIELD GUIDE FOR DETERMINING THE PRESENCE OF FeS IN SOILS

\section{START}

DESCRIBE THE SOIL MORPHOLOGICAL CHARACTERISTICS by recording the matrix color and any contrasting colors (e.g. redoximorphic features). Describe soils under moist condition.

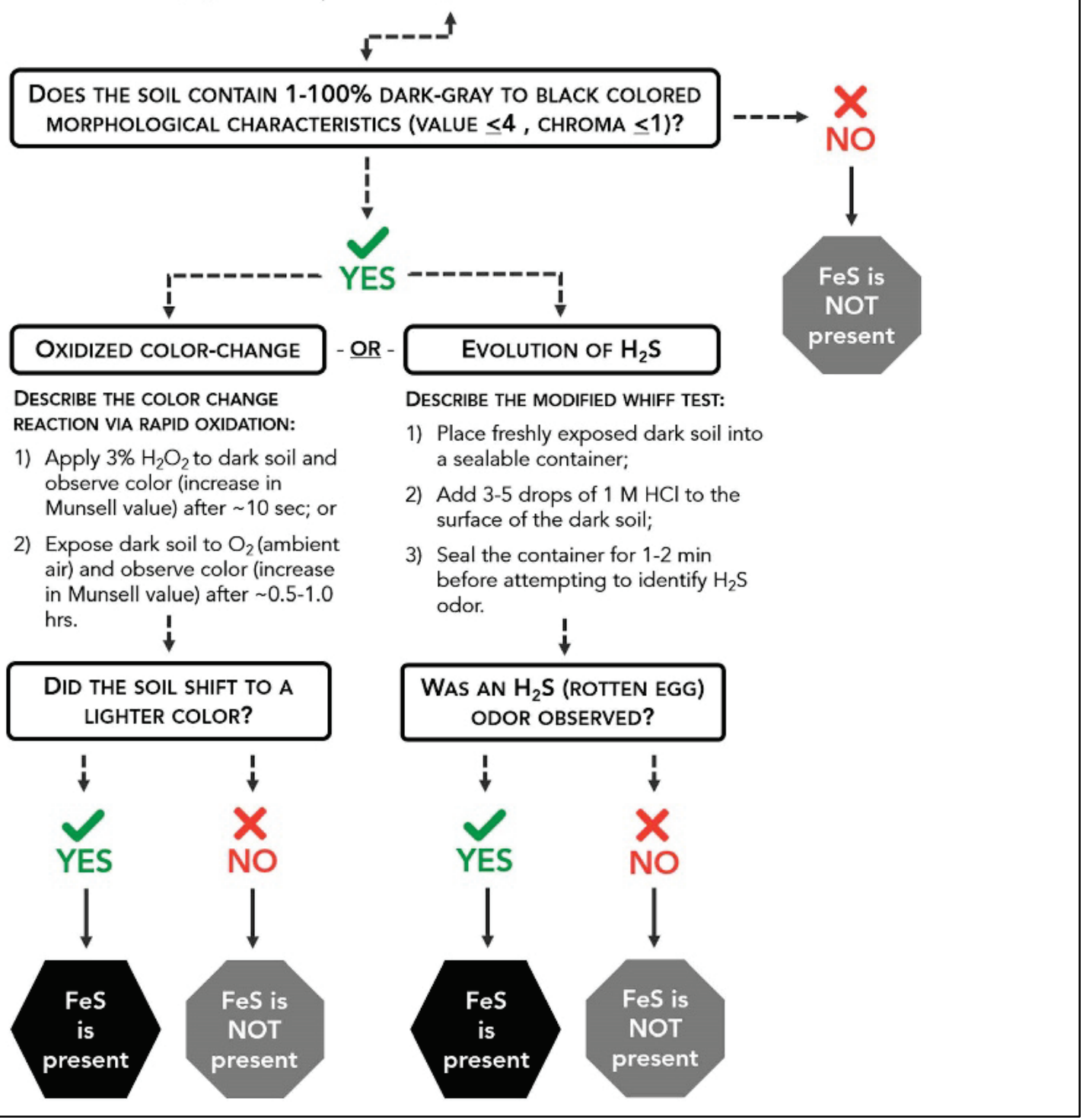

Figure 4. Flowchart (from Duball et al. 2020) depicting the procedure used to identify potential acid sulfate soils in the field. FeS = iron sulfide soil materials (that is, potential acid sulfate soils); $\mathrm{H}_{2} \mathrm{O}_{2}=$ hydrogen peroxide; $\mathrm{HCl}=$ hydrochloric acid; $\mathrm{H}_{2} \mathrm{~S}=$ hydrogen sulfide gas.

It should be noted that other dark materials occur in soils that have the potential to confuse practitioners when evaluating the potential presence of acid sulfate soils. These includemanganese (Mn) oxides, organic matter (that is, dead and decomposing plant materials), and charcoal. While these materials have some of the same color characteristics as potential acid sulfate soils, they do not respond to oxidation (via hydrogen peroxide or exposure to the atmosphere, including a color shift) or application of hydrochloric acid (evolving hydrogen sulfide gas) as described above. To 
avoid the misidentification of potential acid sulfate soils, Duball et al. (2020) developed a comparison chart (figure 5) to aid in field investigations and preclude confusion.

\begin{tabular}{|c|c|c|c|}
\hline & $\begin{array}{l}\text { Appearance and } \\
\text { morphology }\end{array}$ & Reaction to $3 \% \mathrm{H}_{2} \mathrm{O}_{2}$ & Reaction to $1 \mathrm{M} \mathrm{HCl}$ \\
\hline $\mathrm{FeS}$ & $\begin{array}{c}\text { dark gray to black; } \\
\text { coatings, soft masses, } \\
\text { pore linings }\end{array}$ & $\begin{array}{c}\text { immediate color } \\
\text { change, increase in } \\
\text { value }\end{array}$ & $\begin{array}{l}\text { production of } \mathrm{H}_{2} \mathrm{~S} \text {, } \\
\text { rotten egg odor }\end{array}$ \\
\hline Mn oxides & $\begin{array}{c}\text { purple to black; } \\
\text { coatings, soft masses, } \\
\text { pore linings }\end{array}$ & $\begin{array}{c}\text { effervescence, } \\
\text { no color change }\end{array}$ & $\begin{array}{l}\text { no observable } \\
\text { change }\end{array}$ \\
\hline Organic matter & $\begin{array}{c}\text { brown to black; } \\
\text { stains, organic bodies, } \\
\text { \& coatings with } \\
\text { slippery or greasy feel }\end{array}$ & $\begin{array}{l}\text { no immediate } \\
\text { change }\end{array}$ & $\begin{array}{l}\text { no observable } \\
\text { change }\end{array}$ \\
\hline Charcoal & $\begin{array}{c}\text { black; } \\
\text { stains, streaks, } \\
\text { brittle }\end{array}$ & $\begin{array}{l}\text { no immediate } \\
\text { change }\end{array}$ & $\begin{array}{c}\text { no observable } \\
\text { change }\end{array}$ \\
\hline
\end{tabular}

Figure 5. Summary of iron sulfide soil morphology and the response of iron sulfides to field evaluation techniques (from Duball et al. 2020). The morphology and response of other dark soil materials that could be misidentified as potential acid sulfate soils are also included. $\mathrm{FeS}=$ iron sulfide soil materials (that is, potential acid sulfate soils); $\mathrm{H}_{2} \mathrm{O}_{2}=$ hydrogen peroxide; $\mathrm{HCl}=$ hydrochloric acid; $\mathrm{H}_{2} \mathrm{~S}=$ hydrogen sulfide gas. 

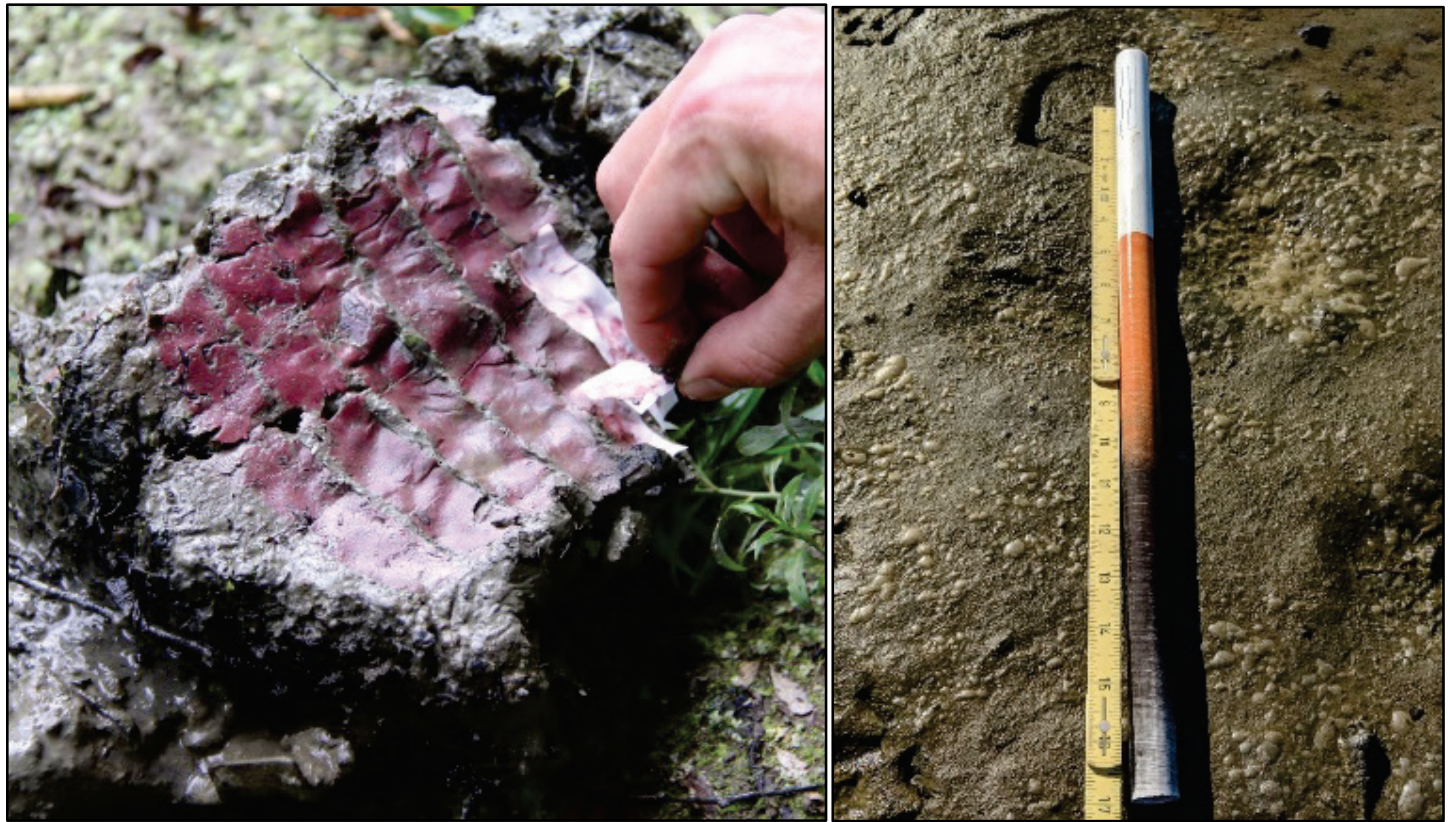

Figure 6. A positive reaction to alpha-alpha dipyridyl dye results in the development of a red or pink color, which indicates that ferrous iron is present in soil solution (left). Development of dark colors on IRIS devices demonstrates that sulfide ions are present in soil solution (right). Collectively, confirming the presence of ferrous iron and sulfides shows that environmental conditions exist to develop iron sulfides in the soil.

Two other techniques can be employed to investigate the potential for iron sulfide formation in wetlands: application of alpha-alpha dipyridyldyeand installation of indicator of reduction in soils (IRIS) devices coated in iron. While the dye and IRIS devices do not directly confirm the presence of potential acid sulfate soils, they can be used in conjunction with the techniques outlined above to determine whether the constituents required for the formation of $\mathrm{FeS}$ (and consequently acid sulfate soils) are present in the environment during a site visit. As noted above, acid sulfate soils form following the chemical reduction of ferrous iron and sulfide ions, which react to form the iron sulfide precipitates. First, alpha-alpha dipyridyl is a chemical dye that generates a pink or red color in the presence of ferrous iron (figure 6 ). The reaction is rapid ( $<2 \mathrm{~min}$ ), and a positive dye reaction documents that one of the components (ferrous iron) required for iron sulfate formation is present. The dye is available in solid or liquid formulations, but we recommend field practitioners use paper test strips that have the dye embedded (Berkowitz et al. 2017). These test strips are commercially available under the name dipyridyl paper.

A variety of IRIS devices coated with iron oxides have been developed to document the presence of anaerobic conditions in wetland soils, and the utility of using these devices to identify the presence of sulfides in soil solution has been recognized (Rabenhorst, Megonigal, and Keller 2010). In practice, make a borehole equivalent to the diameter of the IRIS device. Insert the PVC pipe or other IRIS device coated in iron oxides into the soil, ensuring that the device is in contact with the soil. Wait for thirty minutes to one hour. Remove the device and examine it for the presence of dark materials adhering to the device surface. If sulfide ions are present in the soil solution, the reddish orange (rust-colored) iron coating will have been replaced or covered with dark- or black-colored iron sulfide precipitates (figure 7). A positive reaction indicates sulfides are 
present and reacting with the iron oxides (identified by the precipitation of dark materials on the IRIS device), and therefore the potential exists for acid sulfate soil formation. The dark precipitates on the IRIS device will rapidly oxidize following exposure to the atmosphere, so users should be prepared to document their findings quickly using photographs or other means. Several commercial sources of IRIS devices are now available for practitioners. Only IRIS devices coated in iron (not manganese) are appropriate for this application.

The field techniques described herein provide rapid diagnostic evidence of the presence of iron sulfides and potential acid sulfate soils. These techniques can be applied prior to restoration activities as well as for monitoring over time to determine whether acid sulfate conditions are developing. These approaches can also help determine whether conditions are changing in a project area in response to a management action. When possible, apply multiple techniques to yield as much data as possible, better inform project management, and improve your understanding or the system.

In some cases, a simple presence-absence analysis may address concerns related to the potential presence of acids sulfate soils. However, field investigations do not yield information regarding the concentration of the materials or the acid-generating capacity of the soils. Answering these questions requires laboratory analysis.

Laboratory identification. Many laboratory techniques are available to evaluate potential acid sulfate soils. The sections below focus on the two most common approaches: (1) aerobic incubation and (2) acid-base accounting methods. Both techniques demonstrate that potential acid sulfate soils occur in a sample and provide information as to the extent of the acidification possible under controlled conditions. These approaches are more time consuming and expensive than the field techniques previously described. However, we recommend them when soil acidity is actively being produced, soil acidification has occurred and requires remediation, or practitioners are aware of the presence of potential acid sulfate soils and need information to determine the risk to planned or ongoing restoration activities.

Approach 1: Aerobic incubation. The initiation of acid generation following aerobic incubation has been integrated into the technical definition of potential acid sulfate soils (VanZomeren et al. 2020). The technique is relatively easy and straightforward, requiring that the $\mathrm{pH}$ of the soil be monitored weekly over an 8-16 week period during which the soil sample is exposed to the atmosphere. Soils are collected in the field and returned to the laboratory, where they are placed on the bench top and left uncovered. The soil $\mathrm{pH}$ is monitored weekly and recorded. In some cases, small amounts of water must be added to produce a slurry, allowing the $\mathrm{pH}$ measurements to be made, but otherwise the soil is not manipulated. 


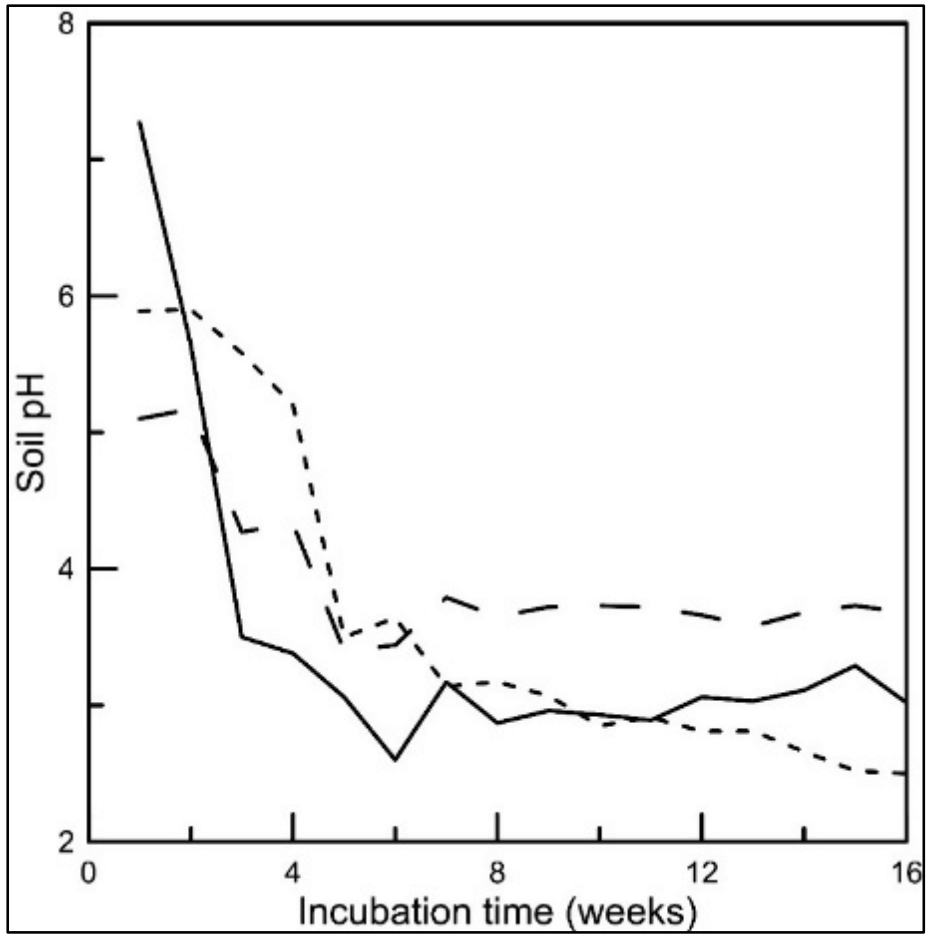

Figure 7. Example of aerobic incubation results for three soil samples. Note that the soils meet the technical definition of acid sulfate soils because they displayed initial $\mathrm{pH}$ values $>3.5$ and underwent a decrease in $\mathrm{pH}$ of 0.5 unit or more, resulting in a final $\mathrm{pH}$ that was $<4.0$ over the 16 weeks of incubation.

The presence of potential acid sulfate soils is confirmed if the soil has an initial $\mathrm{pH}$ value of $>3.5$ and contains sufficient oxidizable sulfide compounds to produce a $\mathrm{pH}$ shift of $>0.5$ units, resulting in a final stable $\mathrm{pH}$ value $<4.0$ following an $8-16$ week aerobic laboratory incubation (figure 7; Sullivan et al. 2009). The aerobic incubation method is relatively inexpensive and provides definitive evidence that a soil or sediment contains materials capable of generating acidity. Additionally, the results of the incubation provide a rough estimate of the magnitude of gross acidgenerating potential. However, the incubation does not account for relevant environmental factors, including tidal flushing and buffering. As a result, the results of the aerobic incubation do not directly reflect real-world conditions and may represent a worst-case scenario in some circumstances.

Approach 2: Acid-base accounting techniques. The methodologies to quantify the acidgenerating potential of materials were initially developed in response to acid mine drainage problems. However, these methods also apply to potential acid sulfate soils, because they predict the theoretical level of total acidity that a material would generate, known as its potential acidity. Potential acidity is expressed as the amount of agricultural limestone (that is, calcium carbonate equivalent) required to fully neutralize the acid load over an extended period of time. The units of application are commonly reported in tons of calcium carbonate equivalent per 1,000 dry tons of material, which is presumed equivalent to the dry weight of mineral soil or sediment per acre six inches deep (for example, the acre furrow slice). In metric units and scientific literature, the value 
is reported as milligrams per kilogram. The US Environmental Protection Agency (USEPA) standard method for conducting the analysis balances maximum potential acidity production from oxidation of sulfur-bearing compounds against the neutralization from carbonates and other alkaline components in the soil material to produce an estimated lime requirement, which is then expressed as net neutralization potential (Sobek et al. 1978; Sobek, Skousen, and Fisher 2000). This is considered a conservative approach that has been used to determine the amount of lime required to mitigate the effects of soil acidification. The method is considered conservative because it assumes that all sulfur compounds in the soil will undergo oxidation; however, in wetland soils substantial amounts of sulfur can be complexed with organic matter, making them less available for oxidation and subsequent acid production.

In practice, however, the liming rates recommended through the acid-base accounting procedure are often increased by a factor of 1.5 to 2.0 . This is done to ensure that the $\mathrm{pH}$ of the material will remain $>5.5$ and that the effect of remedial actions will persist over time even if the soil continues to generate additional acidity. As this analysis requires a combination of laboratory procedures beyond the capabilities of many standard laboratories, assistance from a soil scientist is recommended if application of acid-base accounting is warranted. In instances where soil acidification has already occurred, this approach is recommended to identify appropriate remedial actions.

ACID SULFATE SOILS AND ECOLOGICAL RESTORATION: There are several ways in which the potential acid sulfate soil can affect restoration activities. First, natural processes, including droughts, can induce soil acidification, which in turn can have negative implications for flora and fauna at restoration sites or in the surrounding area. Second, activities conducted as part of a restoration project can induce or exacerbate the potential for soil acidification. Examples of this include excavation of subaqueous soils or sediments that contain acid-bearing materials from stable anaerobic conditions with subsequent exposure to the atmosphere, oxidation, and acid generation. This soil acidification has been observed, for example, following the establishment of upland dredged-material placement areas in Chesapeake Bay (Demas et al. 2004).

Additionally, restoration activities that alter hydrologic regimes, including the construction of dikes, drainage of wetlands and nearshore environments, and other manipulations, have the potential to alter soil acidity. For example, Portnoy (1999) documented changes in soil biogeochemistry and soil $\mathrm{pH}$ following manipulation of diked wetlands in New England.

If soil acidity negatively affects restoration sites, then additional activities may be needed to monitor or remediate the site. The need for remediation of soil acidity that develops following ecological restoration activities often requires acid sulfate soils identification, monitoring, and analysis. For example, recent restoration activities in New England removed dredged materials deposited on marsh surface several decades ago. The project intended to re-establish the natural marsh elevation and predisturbance patterns of tidal inundation and to promote the development of appropriate marsh plant communities to provide habitat for native fauna. Unfortunately, soil acidity derived from sulfur-bearing compounds has negatively affected the project, precluding the successful establishment of robust plant communities (Berkowitz and VanZomeren 2020). Additional measures to remediate the current acid load and preclude future acidification would improve conditions and promote successful restoration at the project location. The following section first discusses several practitioner considerations related to acid sulfate soils within an 
ecological restoration context and then highlights available resources to aid in project design, implementation, and monitoring.

Preproject assessments: During project planning and early design phases, screening efforts should be used to identify potential acid sulfate soils (1) at the project site and (2) within any materials that will be used during project construction. Screening should begin with off-site analysis, such as of geologic feature maps and soil survey data, and then information should be gathered concerning previous construction in the region that may have affected acid sulfate soil conditions. Measurement of soil or sediment $\mathrm{pH}$ and application of the field-evaluation approaches described above should be incorporated into initial project area surveys and other on-site assessments.

Screeningefforts should also evaluate any preliminary sampling of dredged materials or other soils and sediments derived at or near the project location as well as materials that will be transported to the site from other locations. In particular, the need for screening should be incorporated into contracting documents to ensure that environmental consulting and construction firms do not inadvertently expose potential acid sulfate soils to oxidation or use these materials inappropriately during construction. The preproject assessment can apply the techniques described herein for field and laboratory evaluation of potential acid sulfate soils (Duball etal. 2020). If evidence of potential acid sulfate soils is found, the spatial distribution of the materials should be mapped and documented in the project record for incorporation into the later design phases of the project.

Implications for restoration project design: If potential acid sulfate soils are identified during screening, efforts should be made to avoid the use of those materials or ensure that their use in the restoration project does not result in oxidation and acid generation. This measure can be accomplished by designing the project to leave areas with potential acid sulfate soils undisturbed or by ensuring that the materials remain under environmental conditions that maintain anaerobic conditions and prevent oxidation. In general, the like-to-like principle applies here, in which soils and sediments existing under anaerobic conditions continue to experience anaerobic conditions after project implementation. This step will prevent the oxidation of the materials; however, logistical issues related to the collection, transport, and distribution of the material must also be considered. For example, an application that collected soils or sediments containing potential acid sulfate soils with minimal disturbance, transported the soils a short distance, and placed them into a subaqueous location with minimal oxidation potential may be acceptable. However, designs that require extensive transport, store the materials in aerobic conditions for long periods, or distribute the materials in such a manner that would encourage oxidation (for example, hydraulic highpressure discharge, rainbowing) would not be recommended.

If a restoration project area has previously generated or is currently generating active acidity, the acid-base accounting methodology is recommended to estimate the amount of liming materials required to neutralize the existing acidity and buffer against future acid production. The volumes of material required to counteract soil acidity can be large. For example, a recent analysis estimated that 22 tons of liming materials per acre would be needed to neutralize the acidity in a degraded marsh, requiring approximately $80 \times 50$ pound bags of lime per acre. The cost of raw materials and the effort to incorporate that material into the soil matrix can be excessive (estimated costs $>\$ 10,000$ per acre are not uncommon). The potentially high costs required to remediate acidity highlights the need to prevent the occurrence of acid sulfate soil conditions from the beginning. 
Postproject monitoring: Restoration monitoring plans should include postconstruction assessment of acid sulfate soil conditions. This assessment should include measurements of soil $\mathrm{pH}$ as well as the field evaluations of soil conditions described above. If evidence suggests that acid sulfate conditions may be occurring, application of the laboratory analyses presented herein is recommended. Initial monitoring should incorporate sample location with each ecological component of the project. For example, if the project includes three distinct vegetation communities, establishing a minimum of one monitoring location within each vegetation community type is recommended. Similarly, if the project includes multiple hydrologic regimes (for example, different periods of inundation) or landforms, the monitoring locations should be designed to capture the range of hydroperiods and landforms present, which in effect will reflect the gradient of soil oxidation-reduction potentials (aerobic $\rightarrow$ anaerobic) within the project area.

If practitioners are concerned that postproject conditions may result in aeration of potential acid sulfate soil, monitoring plans can also incorporate several other assessment techniques. The installation of IRIS devices, application of alpha-alpha dipyridyl dye (discussed above), or oxidation-reduction probes provide direct evidence of the aerobic or anaerobic status of the soil system (Vepraskas et al. 2016). Further, documenting changes in soil morphology during repeated field evaluations can identify potential shifts in soil conditions, providing rapid identification of potential problems.

Management of restoration areas containing potential acid sulfide soils: While the occurrence of potential acid sulfate soils poses challenges in an ecological restoration context, strategies and tools now exist to appropriately manage these soils and sediments. The most profound issue related to the avoidance of impacts on these soils in a restoration context remains a general lack of familiarity. Many practitioners, environmental contractors, and construction firms have limited awareness of the issue and are therefore ill-equipped to avoid and minimize potential hazards. A strong technical background in soil science, soil chemistry, or the sulfur cycle will help practitioners understand the formation of acid sulfate conditions. However, as this technical note makes clear, the techniques for identifying and monitoring potential acid sulfate soils are generally straightforward, rapid, and inexpensive - and require only limited specialized equipment or technical knowledge. As a result, most practitioners can use them with minimal training. Outreach through local working groups, communities of practice, and other avenues can help manage risk of potential acid sulfate soils during restoration activities.

Regardless of the origin of potential acid sulfate soils, the following three management objectives should be considered when conducting restoration activities in areas where these materials may occur (adapted from Melville and White 2002):

Objective 1: Prevent or minimize oxidation of the acid-bearing materials. This objective may include avoiding some materials, minimizing soil disturbance during restoration activities, or developing design features to ensure that restoration activities do not alter the environmental conditions associated with potential acid sulfate soils. These actions will decrease the risk of acid generation and limit any potential damage to plants and organisms. The most practical approach to prevent oxidation is to maintain saturated soil conditions throughout the restoration project.

Objective 2: Neutralize acidity. If the acidification process is underway, the active acidity and potential acidity can be neutralized via soil amendments. This objective will likely require targeted 
laboratory analysis using the acid-base accounting method or other means to determine the rate of amendment application necessary to ensure that sufficient buffering capacity is integrated in to the project area.

Objective 3: Mitigate potential impacts of acid formation. This objective requires determinations of active and potential acidity as well as soil and receiving water buffering capacity. In some instances, capping acidic materials or neutralization of drainage waters may prove effective.

SUMMARY: The presence or formation of potential acid sulfate soils can have important implications for restoration activities. Fortunately, strategies exist to manage the risks associated with these materials, including opportunities to identify, monitor, avoid, and minimize the risks associated with acid sulfate soils within an ecological restoration context. Notably, as restoration needs and techniques evolve over time, there will likely be new aspects of acid sulfate soil management to consider. For example, practitioners are currently seeking novel and creative ways to beneficially use more available dredged materials to improve environmental outcomes, including thin-layer-sediment applications to raise the marsh platform within the tidal prism. Restoration techniques such as thin-layer sediment seek to re-establish historic hydroperiods, elevation gradients, and landscape features that can alter the environmental conditions related to acid sulfate soils. The recommendations provided here, in addition to ongoing research into the underlying mechanisms supporting iron sulfide development and acidification processes, will aid the design and successful execution of future restoration projects while precluding the negative effects of soil acidification.

ACKNOWLEDGEMENTS:The USACE Ecosystem Management Restoration Research Program provided funding for this work under the direction of Dr. Brook Herman. The authors thank Larry Oliver (NAE), Monica Chasten (NAP), Phil Rosewicz (NWK), David Oster (NAE), as well as Susan Bailey and Nia Hurst (both of ERDC EL) for providing input on this publication. Cite this technical note as:

Berkowitz, Jacob F., and Christine M. VanZomeren. Approaches to Identify and Monitor for Potential Acid Sulfate Soils in an Ecological Context. ERDC Technical Notes Collection. ERDC/TN EMRRP-ER-22. Vicksburg, MS: US Army Engineer Research and Development Center.

\section{BIBLIOGRAPHY}

Berkowitz, J.F. and VanZomeren, C.M., 2020. Evaluation of Iron Sulfide Soil Formation Following Coastal Marsh Restoration-Observations from Three CaseStudies. US Army Engineer Research a nd Development Center. ERDC/EL-TR-20-1.

Berkowitz, J.F., Vepra skas, M.J., Vaughan, K.L. and Vasilas, L.M., 2021. "Development and application of the Hydric Soil Technical Standard”. Soil Science Society of America Journal, 85:469-487

Dahl, Thomas E. 2011. Status and Trends of Wetlands in the Conterminous United States 2004 to 2009. US Department of the Interior, US Fish and Wildlife Service, Fisheries and Habitat Conservation.

Demas, S.Y., Hall, A.M., Fanning, D.S., Rabenhorst, M.C. and Dzantor, E.K., 2004. “Acid Sulfate Soils in Dredged Materials from Tidal Pocomoke Sound in Somerset County, MD, USA.” Soil Research 42, no. 6: 537-545. 
Duba ll. C, K Vaughan, JF Berkowitz, MC Rabenhorst, CM VanZomeren. 2020. "Iron Monosulfide Identification: Field Techniques to ProvideEvidence of Reducing Conditions in Soils." Soil Science Society of America Journal.doi.org/10.1002/saj2.20044.

Fanning, D.S., M.C. Rabenhorst, and R.W. Fitzpatrick. 2017. "HistoricalDevelopments in the Understanding of Acid Sulfate Soils." Geoderma, 308:191-206.

Flynn,K. 1995. "Understanding Wetlands andEndangered Species: Definitions and Relationships." Alabama Cooperative Extension System ANR-979.

Jenny, Hans. 2012. The Soil Resource: Origin and Behavior. Vol.37. Springer Science \& Business Media.

Kurth, M., R. Ali, T. Bridges, B. Suedel, and I. Linkov. 2020. "Evaluating Resilience Co-Benefits of Engineering with Nature ${ }^{\circledR}$ Projects.” Frontiers in Ecologyand Evolution 8:149.

Melville, M.D., and I. White. 2002. “Acid Sulfate Soils, Management.” In Encyclopedia of Soil Science; Lal, R., Ed.: MarcelDekker: New York.

Mitsch, W.J., J.W. Day, J.W. Gilliam, P.M. Groffman, D.L. Hey, G.W.Randall, andN. Wang. 2001. "Reducing Nitrogen Loa ding to the Gulf of Mexico from the Mississippi River Basin: Strategies to Counter a Persistent Ecological Problem: Ecotechnology_The Use of Natural Ecosystems to Solve Environmental Problems - Should Be a Part of Efforts to Shrink the Zone of Hypoxia in the Gulf of Mexico." BioScience 51, no. 5:373-388.

NRC (Na tional Research Council). 1995. Wetlands: Characteristics and Boundaries. National Academies Press.

New Jersey Department of Environmental Quality.2015. Coastal Plain Sediments with Potential to Form Acid (Sulfate) Soils. DGS09-2.

Novitski, R.P., R. Daniel Smith, and Judy D. Fretwell. 1996. "Wetland Functions, Values, and Assessment." National Summaryon Wetland Resources. USGS Wa ter Supply Paper 2425:79-86.

Portnoy, J.W., 1999. "Salt Marsh Diking and Restoration: Biogeochemical Implications of Altered Wetland Hydrology." Environmental Management 24:111-120.

Rabenhorst, M. C., and D. F. Fa nning. 2002. “Acid Sulfate Soils, Problems.” In Encyclopedia of Soil Science; Lal, R., Ed.: Marcel Dekker: New York.

Rabenhorst, M. C., S. N. Burch, and D. F. Fanning. 2002. “Acid Sulfate Soils, Formation.”In Encyclopedia of Soil Science; Lal, R., Ed.: MarcelDekker: New York.

Rabenhorst, Martin C., J. Pa trick Megonigal, and Ja son Keller. 2010. "Synthetic Iron Oxides for Documenting Sulfide in Marsh Pore Wa ter." Soil Science Society of America Journal 74, no. 4: 1383-1388.

Sullivan, L.A., N.J. Ward, R.T. Bush, and E.D. Burton. 2009. "Improved Identification of Sulfidic Soil Materials by a Modified Incubation Method." Geoderma 149:33-38.

Sobek, A.A., W.A. Schuller, J.R. Freeman, and R.M. Smith. 1978. Field and Laboratory Methods Applicable to Overburden and Minesoils. EPA 600/2-78-054.

Sobek, A.S., J.G. Skousen, and S.E. Fisher, Jr. 2000. "Chemical and PhysicalProperties of Overburdens and Minesoils.” In Reclamation of Drastically Disturbed Lands. R.I. Barnhisel et a l. (ed.). Agronomy 41:77104. Madison, WI: American Society of Agronomy. 
USDA-NRCS (United Sta tes Department of Agriculture-Natural Resources Conservation Service). 2010. Keys to Soil Taxonomy. Wa shington, DC: Government Printing Office.

USDA-NRCS. 2018. Field Indicators of Hydric Soils in the United States, version 8.2. LM Vasila s, GW Hurt, and JF Berkowitz (eds.) USDA, NRCS, in cooperation with the National Technical Committee for Hydric Soils.

USDA-NRCS. Acid Sulfate Soils in the Coastal and Subaqueous Environment. Soil Survey Technical Note 11.

Wessel, Ba rret M., John M. Galbraith, Mark H. Stolt, Martin C. Rabenhorst, Delvin S. Fanning, and Maxine J. Levin. 2018. "Soil Taxonomy Proposals for Acid Sulfate Soils and Subaqueous Soils Raised by the 8th International Acid Sulfate Soils Conference.”South African Journal of Plant and Soil35, no. 4: 293-295.

Zedler, Joy B. 200. "Progress in Wetland Restoration Ecology." Trends in Ecology \& Evolution 15, no. 10:402407. 